\title{
Adjustable broaching tool for tolerance compensation in precision manufacturing
}

\author{
Emil Nielsen a , Rasmus Eriksen, Nikolas Paldan, and Mogens Arentoft \\ IPU, Process Technology, Produktionstorvet, DK-2800 Kgs. Lyngby, Denmark
}

\begin{abstract}
Current manufacturing of precision tools for machining typically requires processes such as grinding, EDM or laser processing in order to comply with high requirements on tolerances. However even tools manufactured by these processes come short, when a new batch of workpieces are supplied, and their tolerances are not compliant. This approach presents a precision broaching tool for adjusting the inner diameter of an external broach. The tool compensates for the manufacturing tolerance chain of tool and workpieces by up to $37 \mu \mathrm{m}$. The approach is based on conventional shrink fitting of cold forging tools. A numerical and analytical model of the compression is compared with experimental results.
\end{abstract}

\section{Introduction}

The tolerance chain in precision machining is crucial to the realisation of micro mechanical functionalities. It includes manufacturing tolerances of workpieces, tool parts, and positional tolerances. Effects such as strain and rigidity of both the workpiece and tools also play an important role on the precision, as do thermal expansion, load situation and vibrations.

The proposed micro-broaching process is based on cost and precision requirements for a cycloid gear. The gear consists of a macro-scale titanium grade 5 (Ti-6Al-4V) shaft and ring with an approximate diameter of $12 \mathrm{~mm}$, and $38 \mu \mathrm{m}$ high micro teeth from tooth to recess. The workpieces are manufactured by $\mathrm{CNC}$ and grinding, and the tool by CNC and wire EDM. As can be seen in Fig. 1, the tolerance chain exceeds the tolerance of the diameter of the shaft and the ring, which makes the process chain highly incapable. The clearance tolerance is the deviation of both the shaft's and ring's diameter from the nominal diameters, in order for the shaft and ring to match during assembly. The clearance tolerance is $\pm 5 \mu \mathrm{m}$, but for manufacturing just one part, the capability is $\pm 8 \mu \mathrm{m}$. This paper is focused on the shaft shown in Fig. 2.

This paper proposes a novel tool system for the compensation of tolerances of the workpiece diameter, tool manufacture diameter and broaching guidance. The inner broach diameter is adjusted to match the individual workpiece diameters. Workpiece specifications can vary within a batch, from batch to batch, or from supplier to supplier. The same applies for tools. These variations introduce

\footnotetext{
${ }^{\text {a }}$ Corresponding author: ekn@ipu.dk
}

This is an Open Access article distributed under the terms of the Creative Commons Attribution License 4.0, which permits unrestricted use, distribution, and reproduction in any medium, provided the original work is properly cited. 


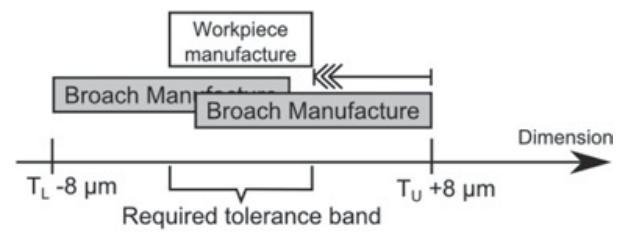

Figure 1. Tolerance chain prior to broaching and required tolerances for broached shafts or rings. Broached shaft.
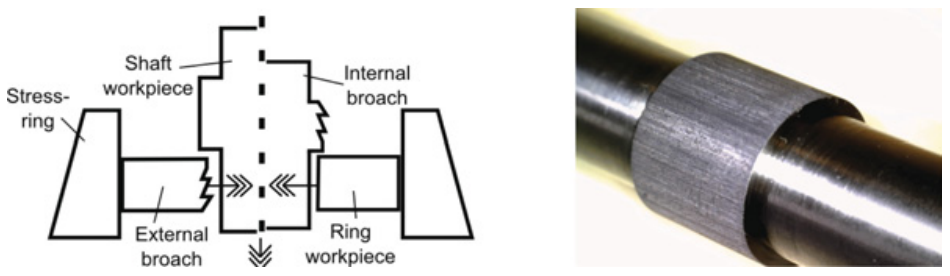

Figure 2. Left: broaching and compression concept for shafts (left) and rings (right); right: broached shaft.

costs as workpieces, processed parts, or tools outside tolerances are scrapped. More strict control of manufacturing tolerances of semi-finished parts and tools is a solution, but it leads to higher costs of manufacturing and quality control. Other ways of mitigating with these variations would be closed loop control of the processes or adaptive control of process parameters to compensate for varying manufacturing system properties [1]. The purpose of this tool is to reduce tool and workpiece costs by reducing scrap, the need for tight tolerances, or the need for tools of different dimensional tolerances. The assembly of gears for this particular application is very time consuming when parts do not comply with tolerances, due to the fact that shaft and ring counterparts are matched on a trial and error basis during assembly.

This approach requires all workpieces to be measured before broaching, and allows for matching out of tolerance rings and shafts. The tool can be set up to broach either rings or shafts. When broaching the shafts, the tool works by compressing an external broach to adjust the inner broach diameter. This is based on a well-established concept from cold forging, exploiting shrink fitting. When broaching the rings, the workpieces (rings) are placed inside a stress-ring instead of the broach as shown in Fig. 2, and the tool works by compressing the workpieces while an internal broach remains unaffected.

\section{Previous work}

Pre-stressing dies by shrink fitting is a known technology in cold forging. The purpose of shrink fitting is to reduce die deflection during forging, hence increasing precision, and to ensure compressive die stresses rather than tensile tangential stresses in order to increase the die life. One of the more recent commercial developments is a strip-wound pre-stressing container with a very high stiffness. The container proved to increase die life with a factor of 3-10, reduce maximum tangential stresses from $1500 \mathrm{MPa}$ to $680 \mathrm{MPa}$, and reduce die deflection with $30-50 \%$. A similar container proved capable of easily adjusting the inner die diameter for spline forming on shafts by $0.01 \mathrm{~mm}$ [2]. A state of the art version of this container, developed to compensate for die manufacture tolerances, tool dimension changes due to temperature and friction, wear, and variations in workpiece, has been used to compensate for dimensional tolerances due to varying radial forces, acting on the inner die diameter during cold forging of gears, caused by workpiece variations [1]. Another tool, capable of compensating for thermal expansion and deflections of the die dimensions, employs a shape memory alloy (SMA) ring between the die and a compression ring. The SMA can resume a previous shape above a critical temperature, and 


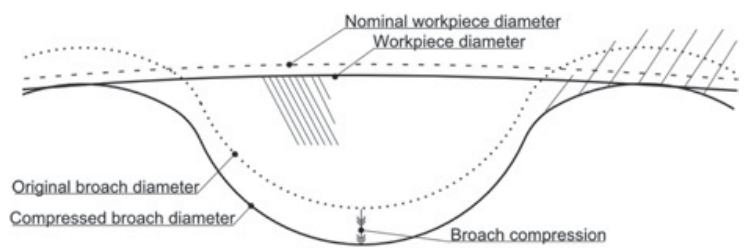

Figure 3. Broach adjustment to workpiece (shaft) diameter.

also gains an increased strength and modulus with increasing temperatures. This allows for an in-process adjustment of the die diameter - a necessity in extrusion and drawing processes [3].

Conventional analytical methods for designing shrink fitted dies and determining the inner die diameter in cold forging includes thick walled cylinder theory $[4,5]$. By the use of FEM the thick walled cylinder approach has shown to be inadequate for designing shrink fits and accurately modelling stresses when applied on gear shaped dies. A hybrid approach for designing shrink fits was proposed, based on correction constants [6]. The constants fit the analytical cylinder approach to similar results from FEM. The purpose was to introduce a set of easy to use equations, for designing accurate shrink fits for cold forging of gears [7].

By using FEM the dimension of cold forged parts has been estimated within $\pm 10 \mu \mathrm{m}$. The approach requires an FEM model for estimation of the pre-stress based on the interference fit, the pre-stress is then applied on a different model with the nominal diameter, as the die diameter is machined after shrink fitting [8].

\section{Broach compression}

The proposed concept adjusts the broach diameter dependent on the workpiece diameter as shown in Fig. 3. The adjustment is carried out between each broaching experiment, by adjusting the shrink fit between a conical nut and a conical stress-ring. As the stress-ring is compressed, the broach or ring inside is also compressed as shown in Fig. 4. The broach can then be adjusted by up to $37 \mu \mathrm{m}$ to compensate for the tolerance chain and broach near net shape teeth independent of the workpiece diameter.

The stress-ring is compressed by screwing the nut onto the screw. The conical surfaces of the stressring and the nut, converts the axial force into a radial force and friction. This compresses the broach, resulting in a reduced diameter. The broach has been manufactured with a diameter $10 \mu \mathrm{m}$ larger than nominal, as it can only compensate for tolerances in one way - by reduction of the diameter and not expansion.

\subsection{Analytical model}

The Analytical model is based on the thick wall cylinder theory [5]. The model does not take the gear teeth into account; hence the inner broach diameter is modelled as flat. The shrink fit pressure $p$ resulting from a specific interference $\delta$ is calculated by Eq. (1). $E$ and $v$ are young's modulus and Poisson's ratio for the broach (i) and the stress-ring (o). The radii can be seen in Fig. 3.

$$
p=\frac{\delta}{\frac{r}{E_{o}}\left(\frac{r_{o}^{2}+r^{2}}{r_{0}^{2}-r^{2}+v_{0}}\right)+\frac{r}{E_{c}}\left(\frac{r^{2}+r_{i}^{2}}{r^{2}-r_{i}^{2}}-v_{i}\right)} .
$$

The broach is subsequently treated as a cylinder subject to an external pressure $p$ from the interference fit with no internal pressure, thus the radial compression $\delta_{r}$ can be found at any given radius $r_{\delta}$ by using 


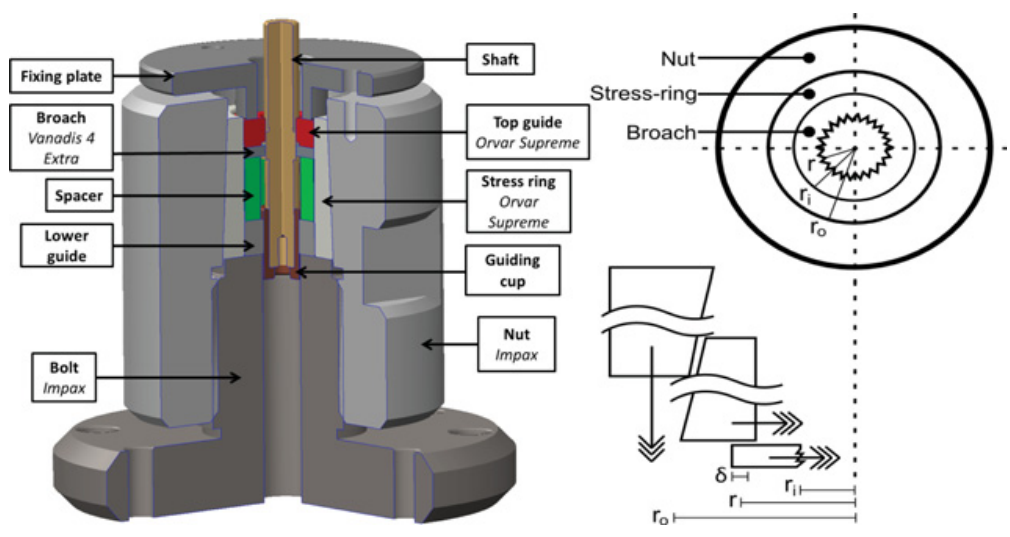

Figure 4. Left: sectional view of the shrink fitting and broaching tool for shaft broaching. Right: top - Shrink fit of nut, stress ring and broach; bottom: displacement of parts.

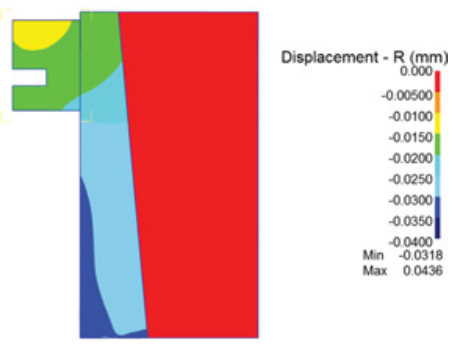

Figure 5. Numerical $60 \mu \mathrm{m}$ shrink fit model showing displacements of nut, stress-ring, broach and top guide.

Eq. (2). In this case the compression is found at the inner broach diameter $r_{\delta}=r_{i}$.

$$
\delta_{r}=\frac{r^{2} \cdot p}{E_{i}\left(r^{2}-r_{i}^{2}\right)}\left[(1-v)+(1+v) \frac{r_{i}^{2}}{r_{\delta}^{2}}\right] .
$$

\subsection{Numerical model}

The numerical model is an initial estimation built in 2D and simulated in DEFORM. It does not include any circumferential gear-teeth as they only make up $0.4 \%$ of the radius, and hence has a limited contribution to the broach stiffness. Nor have friction or the cutting teeth of the broach for machining been included. The model employs a shrink fit between the nut and the stress-ring, resulting in very limited relative motion and thus negligible friction. The displacement of the nodes on the inner broach diameter is measured, as is the mean pressure between the stress-ring and the broach. A simulation of an interference of $60 \mu \mathrm{m}$ is shown in Fig. 5 .

\subsection{Torque and shrink fit pressure relationship}

The torque applied to the nut can be calculated based on a certain shrink fit pressure, from either of the models, in order to predict the resulting compression. The force $F_{\text {Compression }}$ acting on the broach and the top guide due to the pressure $p$, is of the same magnitude as the opposite acting reaction force on the stress ring. The forces for the following equations can be seen in Fig. 6. 

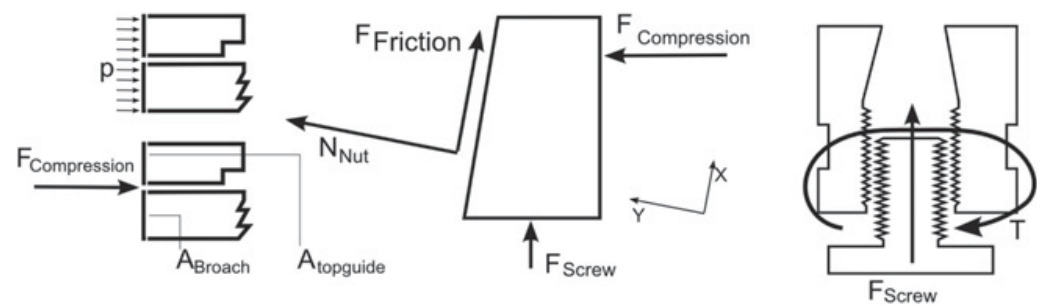

Figure 6. Left: force acting acting on broach and top guide; middle: free body diagram of stress-ring; right: applied nut torque and resultant axial screw force.
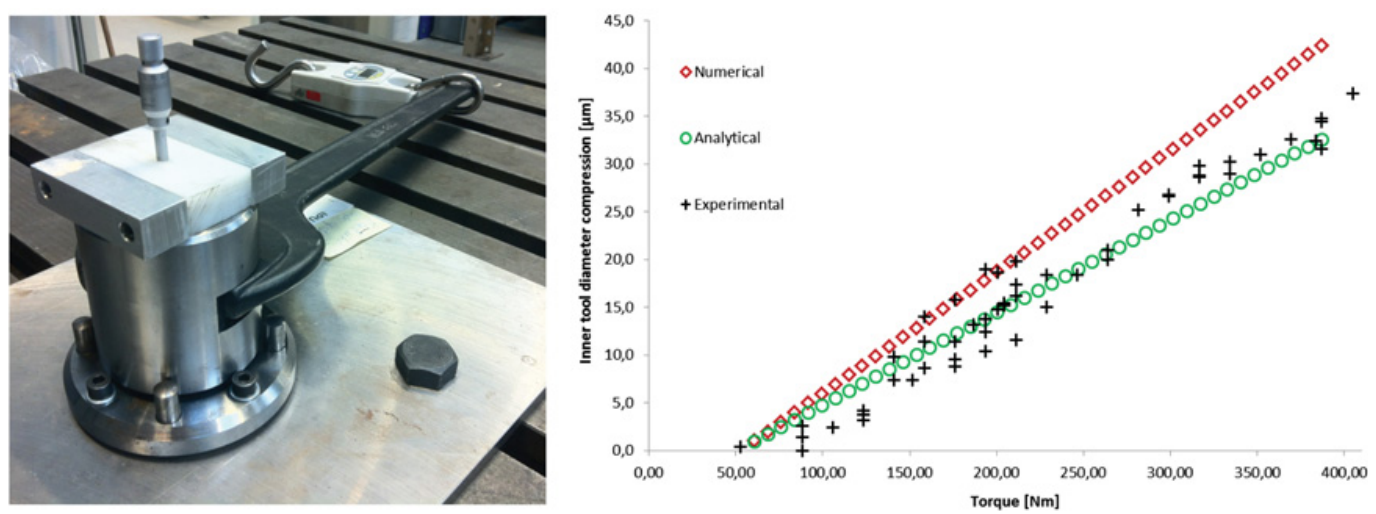

Figure 7. Left: setup for tool compression and inner broach diameter measurements; right: graph of experimental, analytical and numerical inner broach diameter compression as a function of torque.

Equations (3)-(5) are used to calculate the required torque for broach compression, where $K_{i}$ is the torque coefficient, which can be approximated to 0.21 for lubricated threads with a coefficient of friction of 0.15 [9]. The equations are based on the free body diagram from Fig. 6, where forces are treated as in equilibrium in $\mathrm{x}$ - and $\mathrm{y}$-components resulting in two equations with two unknowns that are solved to find $F_{\text {Screw }}$.

$$
\begin{gathered}
F_{\text {Compression }}=p\left(A_{\text {Broach }}+A_{\text {topguide }}\right) \\
F_{\text {Friction }}=\mu N_{\text {Nut }} \\
T=F_{\text {Screw }} K_{i} d_{\text {bolt }} .
\end{gathered}
$$

\subsection{Experimental verification}

In order to verify the analytical and numerical models, a series of compression experiments are carried out, by compressing the tool and measuring the inner broach diameter. The tool is first fixed to avoid any rotation of the screw. A torque is then applied to the nut by a wrench. The torque can be determined with a resolution of $3.5 \mathrm{Nm}$. The compression setup can be seen in Fig. 5. The inner diameter of the broach is measured by using an internal three-point micrometer clamped in a fixture. The micrometer is from Tesa, and it has an accuracy of $0.004 \mathrm{~mm}$.

The analytical model does not include any gear or cutting teeth of the broach. Previous studies have shown insufficient capability for the thick walled cylinder approach to model stresses in shrink fits of 
Table 1. Fit of models to experimental data.

\begin{tabular}{ccccc}
\hline Tolerance chain & $\mathbf{R}^{2}$ & MAE $[\boldsymbol{\mu} \mathbf{~ m}]$ & Max. error $[\boldsymbol{\mu m}]$ & Min. error $[\boldsymbol{\mu m}]$ \\
\hline Numerical model & 0.71 & $5.9 \mu \mathrm{m}$ & $+12.5 \mu \mathrm{m}$ & $-0.4 \mu \mathrm{m}$ \\
\hline Analytical model & 0.95 & $1.8 \mu \mathrm{m}$ & $+4.9 \mu \mathrm{m}$ & $-4.6 \mu \mathrm{m}$ \\
\hline
\end{tabular}

cold forging tools for gears. In this case however, the analytical model agrees well with the experimental data on deflection given that the coefficient of determination $\mathrm{R}^{2}=0.95$. The analytical model only has a mean absolute error (MAE) of $1.8 \mu \mathrm{m}$ - which is less than half the measurement uncertainty of the internal micrometer. The performance of the two models can be seen in Table 1, and the graphs of the models can be seen in Fig. 6.

The linear behaviour of the models in Fig. 7 is the result of the linear elasticity of the materials below the yield stress. The experimental data is scattered and does not show a strictly linear behaviour. This is the result of clearances between parts, measurement uncertainty of the broach diameter and torque, and form errors, although form errors have been shown to have a negligible influence on stresses in interference fits [10]. Clearances and form errors of contact surfaces also influences the starting point of compression which requires approximately $50 \mathrm{Nm}$. Both the numerical and analytical model have been calibrated to the experimental data, by shifting the starting torque from $0 \mathrm{Nm}$ to $50 \mathrm{Nm}$. The difference in slope between the models is most likely due to the FEM shrink-fit approach, excluding relative lateral motion, and hence frictional loss of the applied torque.

\section{Future work}

Of noteworthy improvements the FEM simulation will be modelled in 3D and include gear teeth, cutting teeth and friction. The clearances between nut and stress-ring and stress-ring and broach, and stress ring and top guide will be included in both the numerical and analytical model, hence giving an estimate of the minimum torque required for compression without experimental calibration. Having an accurate measure of friction in the thread and between the nut, stress-ring and broach, should also increase the accuracy of the models. An angular approach of the nut tightening combined with the applied torque could possibly increase the experimental verification accuracy, as the relationship between the torque and radial wrench displacement is not linear. The broaching accuracy and the relationship between compressed broach diameter and the workpiece diameter will be examined by carrying out a series of broaching experiments of the shaft and the ring.

\section{Conclusions}

A novel tool-system for adjusting the inner broach diameter has been developed, exploiting conventional shrink fitting from cold forging. It has been used for compressing the inner broach diameter with up to $37 \mu \mathrm{m}$ on the diameter. The relationship between the applied torque and the resultant compression of the inner broach diameter has been both numerically and analytically modelled. The thick walled cylinder approach seems sufficient for modelling the compression, despite being inadequate for stresses due to stress concentrations. Clearances and form errors of nut, stress-ring and broach however influences the accuracy of the models. The analytical model fit the experimental data with $\mathrm{R} 2=0.95$ and had a mean absolute error of $1.8 \mu \mathrm{m}$.

\section{References}

[1] P. Groche, B. Heß, CIRP Annals - Manufacturing Tech. 63, 285 (2014)

[2] J. Groenbaek, T. Birker, J. of Mat. Proc. Tech. 98, 155 (2000)

[3] Y. Qin, Intl. J. of Machine Tools \& Manufacture 46, 1253 (2006) 


\section{ICNFT 2015}

[4] K. Lange, Handbook of Metal Forming (1985)

[5] I.H. Shames, F.A. Cozzareli, Elastic and inelastic stress analysis (1997)

[6] M.A. Kutuk, O. Eyercioglu, N. Yildirim, A. Akpolat, J. Mech. Eng. Science, Proc. Instn. Mech. Engrs. 217C, 677 (2003)

[7] O. Eyercioglu, M.A. Kutuk, N.F. Yilmaz, J. of Mat. Proc. Tech. 209, 2186 (2009)

[8] V. Sajeev, L. Vijayaraghavan, U.R.K. Rao, Intl. J. of Mech. Eng. Edu. 28 (2000)

[9] R.L. Norton, Machine Design $3^{\text {rd }}$ Ed. (2006)

[10] H. Boutoutaou, M. Bouaziz, J. Fontaine, Materials and Design 32, 3692 (2011) 